\title{
15
}

\section{MAKING DIALOGUE WORK}

\section{Responsible innovation and gene editing}

\section{Phil Macnaghten, Esha Shah, and David Ludwig}

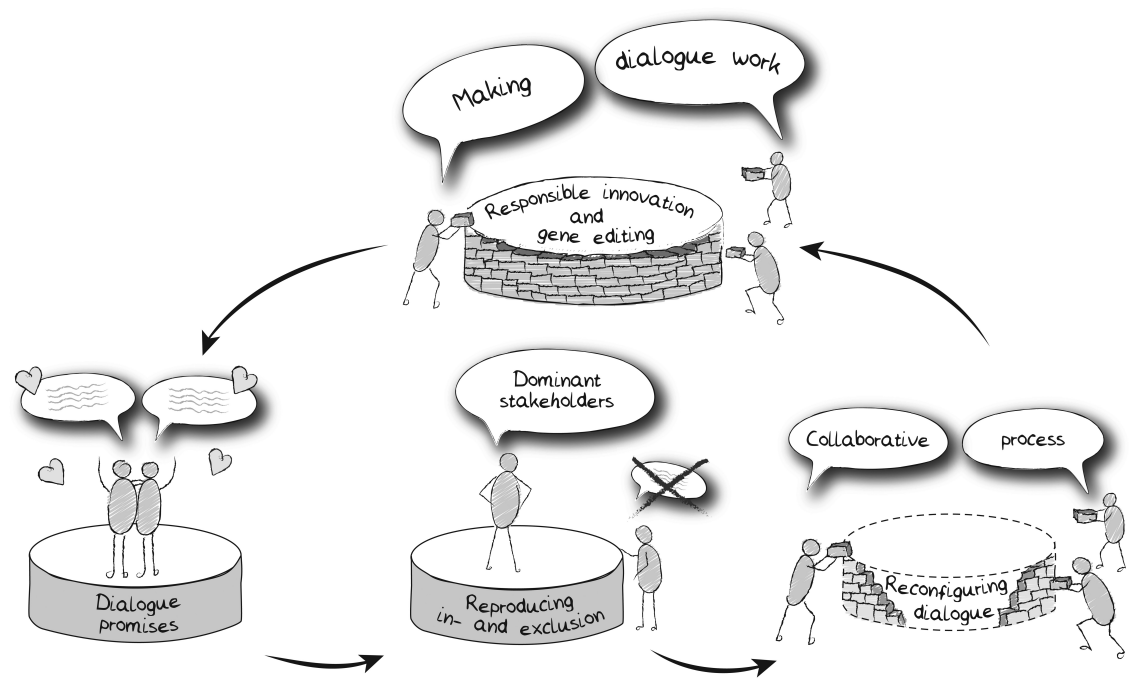

\section{Introduction}

Traditionally, it has been assumed that the institution of science needs little governance; that it should operate as if it was an autonomous republic (Polanyi, 1962). So, the argument goes, as long as internalist norms are upheld which are aimed at guaranteeing scientific integrity-including the Mertonian norms of universalism, communalism, disinterestedness, and organised scepticism-the pursuit of pure curiosity-driven science would operate as the seed from which applied research flourishes, the economy grows and society prosper (Godin, 2006). Yet, 
as the 20th century progressed, this model came increasingly under strain as capable of providing robust governance in the face of real-world harms or unintended consequences that derived from scientific and technological innovation. The initial governance response was to acknowledge that science and technology-even when well conducted-could generate harms and undesired consequences, but that these could be evaluated in advance and within the bounds of scientific rationality through practices of risk assessment. Notwithstanding the efficacy of risk assessment to mitigate the harms associated with science and technology, it did little to anticipate or mitigate a number of high-profile technology disasters that took place throughout the latter half of the 20th century, including the Three Mile Island nuclear accident in the United States in 1979; the Bhopal Union Carbide gas disaster in India in 1984; the Chernobyl nuclear disaster in Ukraine in 1986; and the Fukushima Daiichi nuclear disaster in 2011. Nor did such a model provide authoritative governance in the face of major societal controversy to science and technology, such as the 'mad cow' BSE controversy in the UK and Europe throughout the late 1980s and 1990s, or the genetically modified (GM) food and crop controversy in the 1990s and 2000s first in Europe and then across much of the Global South.

One institutional response to such critique has been the development of initiatives aimed at aligning science priority and agenda-setting processes explicitly to societal challenges. The 'grand challenge' model of science governance best illustrates this approach by focusing the funding of science on core societal problems such as biodiversity loss, sustainable energy production, public health, or poverty reduction. Over the last decade, the grand challenge concept has become deeply embedded in science policy institutions as a central and organising concept that appeals to funding bodies, philanthropic trusts, think tanks, and universities alike. It is as much an organising device for research calls, as it is for research in organisations, notably universities. Yet, even though grand challenges by definition are attempts to respond to society and to public interest, the choice and framing of the challenges themselves tend to be chosen top-down by funding organisations (Calvert, 2013) and in ways that often lend themselves to 'silver bullet' technological solutions (Brooks et al., 2009).

If the grand challenge science governance model seeks to reconfigure the social contract of science such that its core value lies in providing solutions to the world's most pressing problems and not with the pursuit of pure knowledge, the responsible innovation model seeks to reconfigure the social contract in another direction. In contrast with earlier models of science governance, responsible innovation aims to align science and society through inclusive processes that engage with a wide range of stakeholders. In the last decade, responsible innovation emerged as a governance framework both to address grand societal challenges and as a way to 'make science more attractive, raise the appetite of society for innovation, and open up research and innovation activities; allowing all societal actors to work together during the whole research and innovation process in order to better align both the process and its outcomes with the values, needs and 
expectations of European society' (European Commission, 2013: 1). In developing a framework of responsible innovation, debates on responsibility in science are broadened to extend both to their collective and to their external impacts on society, covering both foreseen and unforeseen impacts, alongside assessment of their goals and purposes. More specifically, four dimensions of responsible innovation-anticipation (A), inclusion (I), reflexivity ( $R$ ), and responsiveness ( $R$ ): the AIRR framework- have been formulated to provide a scaffold for raising, discussing, and responding to questions of societal concern, deemed to be characteristics of a more responsible vision of innovation, and heuristically helpful for decision-making on how to shape science and technology in line with societal values (Owen et al., 2012; Stilgoe et al., 2013).

Reconfiguring the relation between science and society along dimensions such as AIRR requires public engagement strategies for opening research and innovation to dialogue among heterogeneous stakeholders. In this chapter, we explore the challenge of aligning science and technology with and for society through an exploration of two case studies that make use of societal dialogues on the future of gene editing.

Gene editing technique CRISPR/Cas is a novel technique for making changes to an organism's DNA. CRISPR is a short term for DNA sequences known as clustered regularly interspaced short palindromic repeats. Scientists use a specific Cas family of enzymes, Cas9 or Cas12, that uses CRISPR sequences as a guide to recognise and cleave specific strands of DNA that are then modified. The gene-editing technqique is thus named CRISPR/Cas, or specifically CRISPRCas9, depending upon the enzyme used to edit genes within any organism. The CRISPR/Cas techinques have made advances in gene-editing arguably more precise, efficient, flexible, and cheaper compared to previous technologies, generating an upsurge of interest in the technique and its multifarious applications. Even though the technique promises benefits — variously defined-it also raises technical, ethical, and societal questions. Since the technology is still largely to be developed into marketable products, it is opportune to open up a conversation with society now; both to better understand public concerns so as to be able to integrate societal values into the science, but more radically, to make the science genuinely more self-reflective, particularly in relation to global challenges such as food security that allow for different responses depending on how the issue is framed and defined.

In the first case, we analyse the dynamics of inclusion and exclusion at a recent CRISPR con conference at Wageningen University, which had been set up as 'a unique forum bringing diverse voices together to discuss the future of CRISPR and gene editing technologies across applications in agriculture, health, conservation, and more' (CRISPRcon, 2020). Here, we scrutinise the linguistic devises, including the 'affective voice' of the conference, assumptions of how gene editing works, and assumptions of societal benefit that were deployed to frame the discussions on societal relevance of CRISPR/Cas gene editing and its products. 
We then set out design principles for an anticipatory or 'upstream' public engagement methodology in deliberative research on new science and technology. Adopting a Science and Technology Studies (STS) perspective, a societal engagement methodology is presented that is aimed at anticipating the kinds of possible and plausible worlds that novel science and technology bring into being. These design principles are then put to use in our second case, a recently conducted focus group project, designed to explore public responses to gene editing in livestock. Reflecting on these two cases, we conclude the chapter on the challenges of making inclusion work in science governance debates, and on how a substantial account of responsible innovation can provide resources for addressing and navigating these challenges.

\section{CRISPRcon: conversations on science, society, and the future of gene editing}

CRISPR con, hosted by Wageningen University and Research in June 2019, was the third so-called 'conversation' of its type organised in partnership with the Keystone Policy Centre. The aim of the conference was to discuss the future of CRISPR and related gene editing technologies across a variety of applications in agriculture, health, conservation, and more. The conference was attended by 156 participants of which the majority were from academia and industry, with $65 \%$ of participants aligned with the food and agriculture sector.

The conversation was hosted under the leadership of the Plant Science Group of Wageningen University and took place in the shadow of the ruling of the European Court of Justice (25 July 2018), at the time one-year old, that had declared that all products of genome editing would be subject to the European GMO Directive. Many scientists at Wageningen University were upset by this ruling because it meant that the elaborate legal control developed for the regulation of GMOs would also be exercised over research and marketing of geneedited plants and animals. The ruling was received among scientists with a sense of disapproval. It was voiced repeatedly that the new science of gene-editing had rendered the old 2001 GMO directive outdated and in need of amendment, with some even going so far as to call the ruling 'anti-science.'

CRISPRcon at Wageningen was organised in an overall 'affective' frame of disappointment, frustration, disbelief, and irritation generated by the Court's ruling-especially among scientists. While this public and policy conversation was set up explicitly as an 'open dialogue,' promising an inclusive conversation 'aimed at the largest cross-section of society' on this new technology, it became a platform for showcasing CRISPR/Cas in a positive light and with immense potential to solve the problems of the world. A question in the opening poll provides a glance at this 'affective' composition of the conference. To the question 'How do you feel about the gene editing future?' The answers were: 44\% enthusiastic, 50\% hopeful, 4\% sceptical, 2\% not sure. We discuss two examples from the conference to explain our argument: first, how throughout the conference the 
science of the CRISPR/Cas gene-editing system was little debated or discussed but presented as a ground-breaking tool with immense potential; and second, how the CRISPR/Cas gene-editing system was discussed as a silver bullet that could solve societal problems, from malaria to food shortage, especially in Africa.

Importantly, in this dialogue on science and society hosted by the life sciences, the complex science of CRISPR/Cas, or even the science of the gene, was neither explained, discussed, nor debated, but exhibited in an overly positive light in what were called 'lightening presentations.' Each lightening presentation was scheduled only for five minutes, compared to an hour allotted to each panel discussion. The time management gave an impression that the conversations in panels were the mainstay of the conference, but looking differently, the lightening presentations highlighted and took for granted the current state of CRISPR/ Cas as a crisp, safe, clean, cheap, easy, and fast tool equipped to solve pressing problems in the agriculture and food and health sector.

For example, one particular lightening presentation posited the 'simple' and 'easy' tool of CRISPR/Cas using the metaphor of 'editing' as a written script at an 'exact' location with a 'precise' outcome explained in the following way: 'Green sea is native to China' is a gene/ text that needs to be edited. In this gene/ text, it is the 'sea' that does not fit and hence represents the 'wrong script'analogous to a mutation causing deadly disease-in need of modification. The CRISPR/Cas tool then puts a cut at the right place and modifies 'the script' to 'Green | sea is native to China,' and then adds the correct script 'green tea is.' This correction, however, results in the incorrect expression 'Gree ntea is native to China,' which is then further repaired to 'Green tea is native to China.' This procedure was explained as analogous to how the system of Cas9 makes a precise cut exactly where it is needed, and how this can develop into one of two scenarios: after the cut either the cellular machinery kicks in to repair the cut by providing random letters that create mutations and thereby inactivate the gene; or, the cut opens a space for the scientists to 'precisely' provide a bare template that can be integrated into the gene, thereby repairing the gene to produce the desired effect. The CRISPR/Cas9 gene-editing tool was thus presented as easy, precise, cheap, fast, robust, and versatile. In both the lightening presentations and also in the panels the CRISPR/Cas system was frequently presented as a tool that could make only 'small' changes to create novel traits in a 'faster way' and hence that could 'speedily' and 'urgently' contribute to solving many of the world's pressing problems. This, we argue, was the first paradigmatic viewpoint of the conference.

'We shall move slowly and carefully' was, on the other hand, the second paradigmatic framing statement of the conference, which we observed to have a more limited effect than the first one. A cautious 'scientist's' voice did emerge in some of the lightening presentations and in the panel discussions. For instance, towards the end of the lightening presentation on the gene editing example discussed above, it was expressed that Cas9 can work only in some cells; that the scientist has to be sure about the availability of target sites to be edited; and 
that Cas9 can also create off-target unintended effects. However, none of these unintended consequences, nor the limits of Cas9, was explained or debated or reflected upon. In another panel discussion one such voice of caution did mention that several publications have shown that CRISPR/Cas9 can also produce unintentional mutations; that it can produce cell level mistakes in copying DNA; and that it can make major changes in the character of the genome. This voice of caution, however, was soon moderated by pointing out that such issues can be solved by locating the desired outcome through the technique of mapping the sequences or improving the protein engineering system from Cas 9 to Cas 12 to make the precise DNA cut, which can deal with the unintended additional mutations, for instance, in experimental field applications. The entire deliberation on the science of CRISPR/Cas gene-editing system was thus palpably presented as a success story with huge potential.

We argue that between these two competing paradigmatic framing statements of the conference-first, that we should enable CRISPR to solve urgent societal problems with speed; and second, that we should move slowly and carefully- the first frame dominated and shaped the overall 'conversation,' often turning into the voice of warning that European science will be left behind and diminished in the global race if so inhibited by the European Court of Justice's ruling.

The first paradigmatic framing statement often became the 'affective voice' of the panel. For example, one of the panellists, a business woman from Uganda, made an emotional appeal to solve the problem of malaria in Africa 'quick and fast,' 'in short time,' and 'now.' This, she claimed she was reliably informed, would be possible by releasing gene-edited mosquitoes into the environment through the technique of gene drives. Yet, surprisingly in a conference of world renowned scientists, there was no discussion of the ongoing debate in scientific communities concerning the growing body of experimental laboratory evidence and literature that has widely challenged the claim that CRISPR-based gene-drive technologies could rapidly eradicate diseases such as malaria, dengue, and zika by driving desired traits into mosquito populations (Alphey, 2016; Sarkar, 2018).

The ineffectiveness of the CRISPR gene-edited drives is attributed to the ontological complexity of the gene and the role of evolutionary processes to have made gene-editing develop into unintended directions (see also Shah et al., draft, for a full-length treatment of this argument). The promises of gene-drive technology to solve the problem of malaria, and of CRISPR gene-edited plant breeding to solve the problem of food shortage in Africa, was repeatedly mentioned several times in the conference. As another panellist pointed out, this 'hope and hype' was reminiscent of two decades of debate on GMOs, in which many similar claims now being made for CRISPR were also made with little success, such as the promise of GM agriculture 'feeding the world' (Macnaghten and Habets, 2020). From a social science perspective, and in the face of a considerable body of literature that has highlighted the need for technological innovation to be situated in larger debates on the socio-political history of agrarian development, it 
is remarkable that no such discussion was afforded in the CRISPR con organised at Wageningen University, where generations of leading social scientists, from Norman Long to Paul Richards to Cees Leeuwis, have done pioneering work.

\section{An anticipatory public engagement dialogue on gene editing}

We have analysed above the dynamics of inclusion and exclusion at the 2019 CRISPRcon event at Wageningen University and Research. We found that far from providing reflexive and critical citizen input on a contested technology as a counterweight to technocratic decision-making, a form of public engagement had been developed that in practice had the effect of reinforcing existing relations of professional power and science policy institutional culturesolidifying dominant models of economic rationality, and reinforcing a quintessentially positive view of what the CRISPR/Cas system is and what it can do. But is such a model of participation as legitimation inevitable? Are other models of doing participation possible? Can reflexive social science move beyond the mode of critique and propose alternative models of doing public engagement for the public good?

In other research we have proposed three operating principles for the enactment of deliberative processes that mitigate against their use as tools of legitimation (Macnaghten, 2020). First, we need deliberative processes where societal actors are offered opportunities for dynamic expression and exploration, and where critique develops as an emergent quality of the process. Second, we need to guard against 'scientism,' the phenomenon where scientific and policy elites impose definitions on the meaning of public issues, foreclosing engagement with broader public meanings and their constituent normative and ontological underpinning. Importantly, these meanings need to emerge through endogenous processes, rather than being imposed either by expert scientific or corporate actors. And third, we need to develop spaces where participants can explore diverse arguments, affectivities, and forms of morality, and through which different identities and meanings can emerge as to the public issues associated with science and technology (Callon and Rabeharisoa, 2004). We now describe how these principles were operationalised in design criteria in a 2019/2020 Dutch NWO-funded project using focus groups - a particular kind of collective- the aim of which was to examine the conditions, if any, under which the technique of animal gene editing is socially acceptable.

The first design feature is sampling: determining who is involved in the deliberative research and the criteria for selection. For our research, using the focus group method, a sampling strategy was designed to be broad and deep. The project involved five groups, with each group meeting for between two hours and two hours 30 minutes. The groups were made up of between seven and nine participants, according to standard focus group norms, and professionally recruited to cover a diverse variety of backgrounds, localities, and 
demographics (age, gender, and socio-economic class) but with topic-specific or theoretically informed variants. These included a group of public sector professionals, another from rural locations, a group of foodies and outdoor enthusiasts, one more of 'involved' mums and dads, and a final one of private sector managers. The decision to involve uninformed participants, who had no particular a priori stake or position in the debate, and who did not know each other prior to the group, is a technique designed explicitly to produce an open-ended sociality, where people develop opinions and attitudes through structured interactive conversation in a safe and empowering space. In this way, the 'anticipatory' focus group methodology creates (albeit temporarily) 'technoscientific citizens' authorised to develop collective views and identities and to open up novel normative and ontological resources for thinking about emerging technology.

The second design feature is context, a neglected aspect in scholarship on deliberative methodology and science communication, but a core element of our methodological design. Given that, by definition, people are unfamiliar with an emerging technology and with the social and ethical issues it presents, it is necessary to explore the context out of which public responses are likely to emerge. Conceptually, it is assumed that it is through contextual factors that people develop an understanding and a relationship to technological innovations as they permeate everyday practice. For our research, the chosen context was animals. It was argued that deliberation on the social practices through which people experience and reflect upon animals in their daily lives-for example, as pets, as livestock, and as food-would illuminate the factors likely to shape responses to applications of gene editing to animals, including their sense of the issues, continuities, and discontinuities between gene-edited livestock and those determined by conventional selective breeding.

The focus groups started with a discussion on how people affectively relate to animals, particularly as pets. What do they like or not like about animals? What is it that builds a good relationship? What are key changes in how we are using and treating animals? What do people feel about eating meat? And how do people feel about different visions on the future of livestock farming represented in four models: an organic farming model, an industrial farming model, a no-livestock farming model, and a precision farming model. These contextual discussions proved enlightening. They revealed the affective and empathetic relations in which animals are regarded in much of daily life; the ambivalence many people feel in eating meat; and a tension between a global commercial system of livestock production and the wellbeing of animals and their rights to live a happy life. Such contextual deliberation helped in the formation of the group identity and underpinned the subsequent and overarching finding that the production of gene-edited livestock would, in the words of one participant, be akin to 'sticking a plaster on a self-inflicted wound.'

The third design feature is framing. Given that the representation of a technology is never neutral but always framed in particular ways and for particular 
purposes, care was exercised to introduce the technology by offering participants an inclusive range of rhetorical resources and frames, without closing down or narrowing the issue in the first place, or presuming that these align with dominant institutional frames and norms. For our research, the CRISPR/Cas system was introduced as a technique, and then in relation to possible and plausible applications both in agriculture and in the human/medical spheres. We then presented participants with four visions of how gene editing in livestock is represented: a positive and promissory vision; a negative and dystopian vision; a case-by-case vision; and a non-ideal vision.

The fourth design feature is moderation. A focus group is more than a group interview or the aggregation of individual opinions and preferences. It is a space in which a group identity and discourse can emerge; where the collective is empowered to articulate the issue at hand in its own terms, and to arrive where possible at the collective production of a group discourse through conversation. The moderator encourages the movement between argument and counterargument in a spirit of mutual understanding. Facilitating a group dynamic and identity is an important accomplishment, as the group has to formulate shared understandings of issues that had been unfamiliar prior to the group discussion. In our research, to ensure that discussions are not framed by expert discourses and norms, the focus groups avoided the inclusion of technical experts. Nevertheless, codified information on what gene editing is, how it works, and what it means, was communicated by the moderator through the use of stimulus materials. Nevertheless, the practical meaning of the technology for the participants was derived through group discussion and deliberation.

The fifth design feature is analysis and interpretation. Our analytical approach is one where the role of the analyst is to become acquainted with the raw data; to organise rhetorical arguments into themes or discourses through the use of codes; to articulate the interplay between thematic concerns and wider social discourses and narratives; and to interpret this meaning within a framework of theoretical and policy concerns. What emerged in our analysis, generally, were thematic questions about purposes ('we need to have a good reason for it'), concerns that the technique in the agri-food domain would be driven principally by commercial imperatives ('this could be so lucrative that companies will move quickly'), about unnaturalness ('you are taking part of an animal's nature away [...] I am afraid nature will strike back'), about perfection ('sounds a bit like eugenics'), about a false solutionism ('maybe we get lax if we think this is an easy solution'), about unanticipated problems ('do we [really] know what it will do') and irretrievability ('if it goes wrong, it really goes wrong'), about the slippery slope ('where does this end'), about distribution of benefits ('the gap will get richer between rich and poor'), about ethical boundaries ('this will create new distinctions'), about control ('if we can decide everything life is no longer fun'), and about desire and excess ("we are so used to wanting more and more and more [...] we should train people "I have enough"—-do I really need it'). Later, when we introduced different frames on the governance of animal gene editing and 
different styles emerging between the United States and Europe, participants expressed support for a restrictive European (and Dutch) approach, for time and care in considering impacts (social, ethical, economic), for public engagement, and for (the Dutch) government to take control.

To summarise, in this section we have described an anticipatory public engagement methodology aimed at structuring a societal dialogue on gene editing and its application to livestock. Through a carefully crafted methodology using focus groups we found a mismatch between: a dominant scientific and policy imaginary of gene editing, as evinced in the paradigmatic framing and affective voice dominating CRISPR con described previously, evoking a characteristically positive view of the technology and its role in solving grand societal challenges; and a more cautious and sceptical approach and affective voice from our public respondents, advocating the need to slow research down, to search for a deeper analysis of our predicament (of which gene editing is a symptom), and to think about the kinds of society we value and wish science and innovation processes to collectively contribute towards. In the concluding section, we examine in more detail this comparison, and the implications for science governance and for a framework of responsible innovation.

\section{Conclusion}

Responsible governance requires responsible dialogues that conform, at least in principle, to the ideal of a free flowing group conversation in which participants attempt to reach a common understanding, and experience each other's point of view fully, equally, and non-judgmentally (Bohm, 1996; Gadamer, 2004). The case of gene editing illustrates both the importance and the challenges of establishing responsible dialogues about emerging technologies, at the intersection of wider hopes and worries about the relation between science and society. On the one hand, gene editing technologies such as CRISPR/Cas integrate into narratives about solving pressing societal problems such as the challenge of 'feeding the world' through cutting-edge science and technology (Gates, 2018; de Wit, 2020). On the other hand, gene editing also integrates into dystopian narratives of scientific hubris that produces outcomes that it can neither foresee nor control such as the infamous 'CRISPR babies' (Lovell-Badge, 2019; Macnaghten and Habets, 2020).

In the introduction, we outlined the development of science governance discourses through three phases: from curiosity-driven science that is detached from societal concerns, to 'grand challenges' science that is focused on solving social-environmental issues, to responsible innovation that aims to align science and society through public engagement. While inclusive dialogues are a crucial element of the responsible innovation model, our first case study of CRISPRcon demonstrates the challenges of making societal dialogue work in the context of emerging and contested technologies. CRISPR con appealed to an inclusive dialogue through presenting itself as a forum for diverse voices to discuss CRISPR. 
However, CRISPR con clearly failed to represent these 'diverse voices,' as it assembled not only a group of stakeholders with overwhelmingly positive attitudes towards gene editing, but that also constructed an affective discourse and frame about revolutionary promises of CRISPR/Cas. The few dissenting voices were pushed to the periphery of this affective discourse later accused the organisers of 'a cleverly choreographed greenwashing rally, funded by corporations such as Bayer and Editas Medicine' (Arora et al., 2019).

The case of CRISPR con highlights the need for caution in moving towards responsible innovation through science-society dialogues. Even frameworks of responsible innovation in terms of (A) anticipation, (I) inclusion, (R) reflexivity, and (R) responsiveness (Stilgoe et al., 2013) can become easily appropriated if not sufficiently specified. At least on the surface, CRISPR con appealed to all four AIRR dimensions by promising an (A) anticipatory dialogue about opportunities and risks of gene editing that (I) included a 'a broad selection of diverse voices' and aimed to increase (R) reflexivity about the future of gene editing by $(\mathrm{R})$ responding to various stakeholders from farmers to industry to the general public. The failure of CRISPRcon to actually create an inclusive dialogue reflects the challenges of moving towards responsible innovation through public engagement rather than reinforcing the perspectives of dominant stakeholders.

If dialogues about emerging technologies are more than a mechanism to legitimise dominant perspectives, they need to incorporate substantive interpretations of what it means to be anticipatory, inclusive, reflexive, and responsive in practice. Our second case study highlights opportunities for moving towards responsible innovation by incorporating these concerns into the design of science-society dialogues. Rather than departing from a vague appeal to 'a broad selection of diverse voices' (CRISPRcon), the focus group design used a clearly defined sampling strategy and topic guide to foster an open-ended dialogue. Rather than choregraphing the affective mood through a focus on revolutionary promises or dystopian risks, the dialogue was designed to open up context, framing, and moderation for collaborative negotiation of heterogenous concerns and issue-framings. None of these design principles provides simple solutions to concerns about the instrumentalisation of dialogue, and they certainly do not lead to a value-neutral negotiation space free of biases. However, each of the five design principles constitutes a tool for navigating tensions in societal dialogues about emerging and contested technologies, for creating a safe space in which competing values and bias can be shared and negotiated, and as such for contributing to responsible, just, and inclusive innovation.

Finally, there is the political dimension to the above analysis. While deliberative processes inevitably involve the strategic use of arguments, the framing of engagement questions and formats, the inclusion and exclusion of particular actors and perspectives, and so on, it is also the case that some deliberative processes are by design more inclusive and reflexive than others. With this in mind, it is arguably the case that the implicit politics of the two cases were demonstrably divergent. While the politics of the CRISPR con case was that of constituting 
dialogue as a means of promoting the technology not least through an overwhelmingly positive affective discourse, the politics of the anticipatory public engagement dialogue was that of designing an endogenous process aimed at developing a collective imagination of the possible worlds enabled by gene editing. How we configure the role of the public in early discussions of a technology-either as in Case 1 as a 'malleable subject' able to have its views and positions bent through the provision of information and argument from gene editing protagonists; or as in Case 2 as an 'exploratory' or 'reflexive' subject able to develop its own positions in its own terms (Macnaghten and Chilvers, 2014) - is ultimately a question for power and politics. Connecting dialogue processes to formal processes of democratic decision-making will be a formidable challenge for dialogue scholars and activists.

\section{References}

Alphey, L. (2016). Can CRISPR-Cas9 gene drives curb malaria? Nature Biotechnology, 34(2), 149-150.

Arora, S., van Dyck, B. and Wakeford, T. (2019). Choreographed consensus: The stifling of dissent at CRISPRcon 2019. The STEPS Centre Blog, 28, 2019.

Bohm, D. (1996). On Dialogue. London: Routledge.

Brooks, S., Leach, M., Lucas, H. and Millstone, E. (2009). Silver Bullets, Grand Challenges and the New Philanthropy. STEPS Working Paper 24, STEPS Centre. Accessed 17 June 2020. http://www.ids.ac.uk/files/dmfile/STEPSWorkingPaper24.pdf

Callon, M. and Rabeharisoa, V. (2004). Gino's lesson on humanity: Genetics, mutual entanglements and the sociologist's role. Economy and Society, 33(1), 1-27.

Calvert, J. (2013). Systems biology: Big science and grand challenges. BioSocieties, 8, 466-479.

European Commission (2013). Fact Sheet: Science with and for society in Horizon 2020. Accessed 17 June 2020. https://ec.europa.eu/programmes/horizon2020/sites/horiz on2020/files/FactSheet_Science_with_and_for_Society.pdf

Gadamer, H.-G. (2004). Truth and Method. New York: Continuum.

Gates, B. (2018). Gene editing for good: How CRISPR could transform global development. Foreign Affairs, 97, 166.

Godin, B. (2006). The linear model of innovation: The historical construction of an analytical framework. Science, Technology and Human Values, 31(6), 639-667.

Lovell-Badge, R. (2019). CRISPR babies: A view from the centre of the storm. Development, 146(3), dev175778.

Macnaghten, P. (2020). Towards an anticipatory public engagement methodology: Deliberative experiments in the assembly of possible worlds using focus group. Qualitative Research, 29(1), 3-19, doi:10.1177/1468794120919096.

Macnaghten, P. and Chilvers, J. (2014). The future of science governance: Publics, policies, practices. Environment and Planning C: Government and Policy, 32(3), 530-548.

Macnaghten, P. and Habets, M. G. (2020). Breaking the impasse: Towards a forwardlooking governance framework for gene editing with plants. Plants, People, Planet, 2(4), 353-365.

Owen, R., Macnaghten, P. and Stilgoe, J. (2012). Responsible research and innovation: From science in society to science for society, with society. Science and Public Policy, 39(6), 751-760. 
Polanyi, M. (1962). The republic of science. Minerva, 1(1), 54-73.

Sarkar, S. (2018). Researchers hit roadblocks with gene drives. BioScience, 68(7), 474-480. Shah, E., Ludwig, D. and Macnaghten, P. (draft). The complexity of the gene and the precision of CRISPR: What is the gene that is being edited?

Stilgoe, J., Owen, R. and Macnaghten, P. (2013). Developing a framework of responsible innovation. Research Policy, 42(9), 1568-1580.

de Wit, M. M. (2020). Democratizing CRISPR? Stories, practices, and politics of science and governance on the agricultural gene editing frontier. Elementa: Science of the Anthropocene, 8(1), 9. 